\title{
Why heaven doesn't make earth absolutely meaningless, just relatively
}

\author{
T. J. MAWSON \\ St Peter's College, Oxford, OX1 2DL, UK \\ email:tim.mawson@philosophy.ox.ac.uk
}

\begin{abstract}
In this paper, I seek charitably to develop an argument suggested by Thad Metz. This is an argument against the view that it is consistent to hold that, whilst our lives may have some meaningfulness even if there is no heavenly afterlife awaiting us, if there is such an afterlife, they are even more meaningful for heaven adds a potential infinity of meaningfulness. Having developed this argument on Metz's behalf, I criticise it. I conclude that - whilst throwing out a number of interesting ideas and possibilities along the way - no argument along Metz's lines can finally reach the conclusion aimed for.
\end{abstract}

First, I shall spend a moment or two localising the argument I shall be developing and evaluating in the wider landscape of the meaning debate.

I have myself argued that when one asks, 'What is the meaning of life?' one asks a number of different questions at once and these questions have a number of different answers. Nevertheless, if one narrows in on what is, I contend, just one section of one's concerns in asking the question, then the contemporary literature, which focuses on this section (often to the exclusion of other issues) ${ }^{1}$, gives a number of plausible accounts of what it is that makes an individual's life more or less meaningful. Meaningfulness then is characteristically taken in the contemporary literature to be a single final gradient value in individuals' lives, one that is to be distinguished from happiness, virtue, and others. On my own view, we do best by thinking of these accounts of meaningfulness as ways of capturing different aspects of its polyvalent (as I have called it) nature. According to me, meaningfulness isn't really one feature that our individual lives may have to a greater or lesser extent, but many features. Using the term 'meaningfulness' then to refer to this group of features of individuals' lives, I have argued for the view that, whilst some relatively shallow or transient meaningfulness is available to us even if we in fact live in a world in which there is no God and no heavenly afterlife awaiting any of us, if Theism (the view that there is a theistic God) and Universalism (the view that everyone gets to Heaven) are true, then deeper and more long-lasting (indeed potentially infinitely long-lasting) meaningfulness is available to us. ${ }^{2}$

It's this last claim - that God and Heaven add to our lives' meaningfulness, though some at least is possible even if there is no God and Heaven - that is cogent to the concerns of this paper; and it's the long-lastingness of what God adds through Heaven that is most cogent. It is worth noting that the claim that God and Heaven add meaningfulness, even though absent them our lives still have some meaningfulness, is available to those who do not share the 'polyvalence' view that forms the background to it for me and that it is quite widespread across the theistic community. ${ }^{3}$ The view that if there were to be a God and a heavenly afterlife for all of us, then our lives (as ante-mortem plus post-mortem lives) would be more meaningful than in fact they actually are (given that there are in fact neither of these things) is also quite widespread amongst atheists. ${ }^{4}$ Indeed, the view that God adds (or would add) to our lives' meaningfulness, but we would not be (or are not) totally devoid of meaningfulness without Him, is arguably the consensus view along the theist/agnostic/atheist 
spectrum. ${ }^{5}$ In any case, the view that Metz sets out to show is untenable is by no means a view that nobody holds.

There are, I have suggested, a number of lines of argument leading to the view that God and a heavenly afterlife add to our lives' meaningfulness, but the line of argument most cogent to the counter-argument to it which I wish to consider in this paper is the simplest. I call it the 'quantitative' point'. In short, the quantitative point goes like this. Take whatever meaningfulness our ante-mortem lives have. Allow that amount, for the sake of argument, to be fixed whether we're in a world in which Atheism is true or in a world in which Theism and Universalism are true. On Atheism (in its most plausible variants), that is all the meaningfulness our lives have, for our ante-mortem lives are all the lives we have. On Theism plus Universalism, however, this is just the beginning of the story. Our post-mortem lives add to the total meaningfulness and - as Heaven is everlasting - they add ad infinitum to the meaningfulness of our lives; the story never ends.

There are a number of arguments which one might deploy against the quantitative point, but one counterargument is, I believe, a relatively recent one, emerging only in the last few years and only in the writings of the philosopher who, more than any other, has brought analytic rigour to philosophical reflection on the topic of life's meaning - Thaddeus Metz. ${ }^{6}$ It is this counter argument to the quantitative point that I shall develop and assess in this paper. Whilst I do not agree with this counter-argument, I think it is very fruitful - throwing out a number of interesting ideas and possibilities, ones the depths of which I shall not be able to plumb here. I hope only that I shall be a reliable guide to their shallows. ${ }^{7}$

So, what is this counter-argument to the quantitative point? Here are some indicative quotations from Metz.

The logic of this [the quantitative] rationale threatens to render it unable to capture the essential intuition...that a meaningful life without God is possible. If an eternal afterlife spent with God would enhance meaning in our lives, it would do so to such a huge extent as to make it unreasonable to judge an 80 year life to be capable of being meaningful. Compare the degree of meaning in an immortal life in Heaven with the degree available to a mortal life. It would be infinitely larger. And if such a life would be infinitely more meaningful than a mortal one, then the grounds for claiming that a mortal life could be meaningful on balance fall away. It would be like saying that a house can be big, even if it would be bigger were it to grow to be the size of a billion billion billion suns.' [He then quotes me arguing in a similar vein to the manner in which I have just argued, before going on.] 'To be sure, by this position, Gandhi's life would not be a 'flat zero', but it would, compared to infinity, come about as close to zero as is mathematically possible for a non-zero number, and that arguably fails to capture the judgment that Gandhi's life was meaningful on balance absent God and a soul. Just as we would not describe someone's life as 'happy' if it had only a smidge of happiness compared to what is frequently on offer, so we cannot plausibly describe someone's mortal life as 'meaningful' if it has only a small dollop of meaning compared to infinity. ${ }^{8}$

On another occasion, of the point that in comparison to the amount of meaningfulness that we are, on Theism plus Universalism, destined to enjoy, even the meaningfulness that could be enjoyed over a lifespan of several millennia would tend to nothing, he says the following.

I take this point to be damning, since the intuition that Mawson is - and should be - seeking to capture is that a meaningful life on balance is possible in an atheist world, just not the sort that is most desirable. Mawson needs to be able to conclude that the lives of Einstein, Mandela and van Gogh would still have been meaningful to a real degree in the absence of God and Heaven. He needs to account for his own intuition that [quoting me] 'Gandhi's life is more meaningful than that of the wastrel' in the absence of a (Godly) Heaven....Mawson can conclude that a theist world could make life 
much more meaningful than an atheist world, but only at the cost of having to forgo the firm judgment, which he shares, that some substantial meaning is still possible in the latter world. ${ }^{9}$

There are a number of things going on in these passages and similar ones in the writings of Metz on this point, or at least a number of things that may be going on in them. My intention then in what follows is charitably to develop an argument from some of the ideas in such passages against the quantitative point, prior to assessing the Metz-inspired argument that I shall by then have developed.

With that aim in mind then, let's consider two worlds, which I shall call 'Atheism World' and 'Theism-Plus-Universalism World'. Each of these is, apart from the issue of the existence of God and Heaven, as similar to one another as they can be and each of these is as similar to the actual world as it can be. ${ }^{10}$ We may say that Atheism World is the world most atheists believe to be actual and Theism-Plus-Universalism World is the world which most theists who are universalists believe to be actual. Atheism World then, as I am encouraging us to imagine it, is a world where there is no 'ersatz' God providing an afterlife for us. Rather this - ante-mortem - life is all that there is. Theism-Plus-Universalism World is a world where - after this ante-mortem life - we all go to enjoy an everlasting post-mortem life with God in Heaven. ${ }^{11}$ Let us allow ourselves some arbitrary way of metricising how meaningful sections of an individual's life are. And let us stipulate that, using that metric, it comes out that Gandhi (someone who we may take it for the sake of argument we will want to say had a significantly meaningful ante-mortem life) had 1000 units of meaningfulness in his antemortem life. Tibalt (who we specify as someone whose only activity was to collect miniature teapots and thus who we may take it for the sake of argument we'll want to say had an antemortem life almost devoid of meaningfulness) had 5 units of meaningfulness in his antemortem life. ${ }^{12}$ Then we may represent the situation thus:-

Table 1: Atheism World

Amount of meaningfulness

$\begin{array}{llll} & \text { Ante-mortem } & \text { Post-mortem } & \text { Total } \\ \text { Gandhi } & 1000 & 0 & 1000 \\ \text { Tibalt } & 5 & 0 & 5\end{array}$

Now we turn to consider how we should draw up the table for Theism-PlusUniversalism World. The following is how Metz would encourage us to draw it up.

Table 2: Theism-Plus-Universalism World

Amount of meaningfulness

$\begin{array}{llll} & \text { Ante-mortem } & \text { Post-mortem } & \text { Total } \\ \text { Gandhi } & 1000 & \text { INFINITY } & \text { INFINITY } \\ \text { Tibalt } & 5 & \text { INFINITY } & \text { INFINITY }\end{array}$

However, this is not quite right; this table doesn't represent a state of affairs that will ever be realised, but rather one towards which reality tends in Theism-Plus-Universalism World. In Theism-Plus-Universalism World, given we will never actually have lived an infinite time, the amount of meaningfulness our lives will ever contain is always going to be a potential infinity, not an actual infinity, i.e. it will always be finite. Thus, on a principle which we shall see Metz in fact needs to make his own argument work (that, when assessing relative meaningfulness, suitable comparators must be drawn from actual lives), Table 2 is not the one we should be considering. ${ }^{13}$ But now there arises the first problem for Metz's line 
of thinking: other tables don't seem so obviously able to fulfil the role that Metz's argument needs them to fulfil. Let's stand back for a moment.

As we are imagining it, Gandhi and Tibalt start off in Theism-Plus-Universalism World. They live out their earthly lives and then they die, Gandhi's score at the moment of death being 1000 and Tibalt's, 5. They then go to Heaven and, after a day in Heaven, let's say each has added to their 'score', D (which is by stipulation the amount of meaningfulness that Heaven gives each of its residents per day ${ }^{14}$ ). Gandhi's life and Tibalt's life as now they may be considered - as composed in each case of their completed ante-mortem section and a day of their incomplete post-mortem section - are obviously more meaningful, each by $\mathrm{D}$, than they would have been had they lived in Atheism World. See table 1, above, and compare it with table 3, below.

Table 3: Theism-Plus-Universalism World, After One Day in Heaven Amount of meaningfulness

$\begin{array}{llll} & \text { Ante-mortem } & \text { Post-mortem } & \text { Total } \\ \text { Gandhi } & 1000 & \mathrm{D} & 1000+\mathrm{D} \\ \text { Tibalt } & 5 & \mathrm{D} & 5+\mathrm{D}\end{array}$

After two days in Heaven, the table will be as follows:-

Table 4: Theism-Plus-Universalism World, After Two Days in Heaven

Amount of meaningfulness

$\begin{array}{llll} & \text { Ante-mortem } & \text { Post-mortem } & \text { Total } \\ \text { Gandhi } & 1000 & \text { 2D } & 1000+2 \mathrm{D} \\ \text { Tibalt } & 5 & \text { 2D } & 5+2 \mathrm{D}\end{array}$

And so on. With each day that passes in Heaven, the lives of Gandhi and Tibalt will be getting more meaningful (by D in each case) than their lives would have been had they been in Atheism World (see table 1 again). If no day in Heaven would break this pattern, then why does Metz say that there is some problem in saying that the lives of everyone in TheismPlus-Universalism World are destined to be, after their deaths, eventually more meaningful than the lives of everyone in Atheism World? Eventually, the Ds added in the post-mortem columns will make a contribution to the total meaningfulness of everyone's lives, as they'll by then have lived them, which will itself be greater than whatever the greatest score anybody manages to achieve ante-mortem in Atheism World. Thus, the general view that I am encouraging us to adopt - that, even though some meaningfulness is achievable in Atheism World, more meaningfulness is achievable, and indeed is destined to be actually achieved, in Theism-Plus-Universalism World - is supported by the quantitative point. ${ }^{15}$

However, my line of thinking here contra Metz rests on a notion of the absolute meaningfulness of lives. Perhaps one may detect another argument in Metz, one different from that which I've hitherto developed on his behalf. This would be an argument suggested by Metz's use of the word 'big' and 'degree' and his description of our judgments as 'comparative'. And it would be an argument which would sweep such an 'absolute' foundation away in favour of a purely relative notion of meaningfulness. I believe one can detect another argument along these lines in Metz. Further, I believe that it is a more intriguing argument than the one I've hitherto been developing and engaging with, for it doesn't rely on conflating potential infinities with actual ones, using something like Table 2 to make its case. And finally, it throws out more interesting possibilities and considerations as we explore it. Allow me then to do my best to extract charitably that argument against the 
quantitative point, prior to assessing it. Metz himself, I should underscore, never himself develops the argument I am now going to develop on his behalf against the quantitative point, beyond the manner of the quotations from his works already given. That being so, the 'Metzinspired' argument, as I shall incline to call it, which I shall now develop is one which he may not himself wish to claim for his own, especially after I have shown its failings. Still, if he were to disavow this argument, it would then behove Metz all the more to articulate precisely his argument against the quantitative point as he did intend to convey it in these and similar passages. ${ }^{16}$ In any case, I would hope that the Metz-inspired argument I shall develop is sufficiently interesting to merit attention in its own right.

First, an analogy.

We moved house in Oxford some three or so years ago and I am still somewhat surprised when visitors to our new (as I still think of it) house say of it that it is big. But, as I reflect on it and whilst I haven't done the research, I imagine that the floor area of our new house is a notch or two above the average, median or mode floor area for houses in Oxford. It's no doubt with some comparison class like that in mind that I'm to understand claims that our house is 'big' - understand them and indeed agree with them. Were I to seek to contradict one of our visitors on this point by saying that, in comparison with Blenheim Palace, our house is small, that would be - rightly - deemed true but irrelevant to the point they were intending to make. They never meant to claim that our house was big relative to those houses which constitute the class of stately homes or some such, but only relative to those which constitute the class of domestic dwellings in Oxford or some such. And if our house is indeed a good notch or two above the average, median, mode or what have you of floor areas for the houses in this comparison class, then that is sufficient for their claim to be true. If it is not, if it is actually below, then - however roomy it may seem - it is in fact not big. If it is a few notches below, it may even be small. On this understanding of how 'big' works then, which seems right, I could in principle make our house big without doing anything to affect it intrinsically at all. I could simply knock down all the houses in the relevant comparison class that were bigger than it or add enough smaller houses to that class. That's the way the notion of 'big' works. It's linked to some sort of average in a suitable comparison class and means 'some way above that average'. In the long passages from his works which I quoted earlier on, Metz is, I suggest, naturally read as supposing that 'meaningful' functions in a similar way. 'Meaningful' means relatively meaningful, relative to some suitable comparison class and its relative meaning is the only meaning it has. ${ }^{17}$ For Gandhi's life to be meaningful, it must thus be that it is a good notch or two above the average, median, mode or what have you for the suitable comparison class. I speak of being 'a good notch or two' clear of the relevant point primarily in order to remove from consideration vagueness issues, but it does seem right for another reason. Suppose I were to do the research and find out that in fact the floor area of our current house is exactly at the average, median, mode or what have you for the suitable comparison class and thus find out that our house is not yet big. It would seem odd to think I could make our house big simply by adding a square inch in some manner to its floor space. So, to repeat, on this view, 'meaningful' always means relatively meaningful, never absolutely so. And 'relative' means relative to some sort of average. Let's call this the 'Relative to Average' understanding of meaningfulness. Straight out of the gate, as it were, this does not seem too implausible an analysis of meaningfulness and if we do suppose that meaningfulness operates in this way, it seems that the road may be open to a conclusion along Metz's lines. But before proceeding farther down this road, it is worth noting that Metz himself would substitute a slightly different understanding of meaningfulness were he to be pressed at this point and, though such a substitution wouldn't affect the structure of the 
arguments, it is worth noting this, even if only so as to be able to see that such a substitution wouldn't affect the structure of the arguments. ${ }^{18}$ That being so, we'll spend a moment or two on it before moving on.

Metz himself indicates at one stage that he prefers a 'Relative to Maximum' understanding of meaningfulness over a 'Relative to Average' one.

In another piece, focused it should be said on a different set of issues, Metz discusses just such a view as the 'Relative to Average' one and, whilst broadly favourable to it, he in the end finds himself even more favourably disposed towards a slightly different account of how meaningfulness works. ${ }^{19}$ Metz doesn't finally settle definitively in favour of one formulation of this other account, but in its various formulations it shares the feature that it makes meaningfulness relative, not to the average, median, mode or what have you achieved by people in a suitable comparison class, but to the maximum achieved (or characteristically achieved) by people in a suitable comparison class.

Here are his three different formulations:-

A human's life is meaningful on balance just insofar as it is not very far below the maximum amount of final value (relevant to meaning) that a human can achieve, given the laws of nature. ${ }^{20}$

A human's life is meaningful on balance just insofar as it is not very far below the maximum amount of final value (relevant to meaning) that a human is likely to achieve, given the laws of nature. ${ }^{21}$

A human life is meaningful on balance just insofar as it is not very far below the maximum amount of final value (relevant to meaning) that a being that was born human is likely to achieve, given the laws of nature. $^{22}$

Metz's reasons for relativizing to the maximum rather than the average, median, mode or what have you are primarily that, on the average account, 'it is impossible for everyone's life to be meaningful' ${ }^{23}$, which he finds implausible. He says, 'Tallness seems inherently comparative in the sense that something small must exist in order for there to be something tall. However, meaningfulness is not obviously comparative in this way; we can imagine a world in which human lives are all meaningful or all meaningless. ${ }^{24}$ It is not clear how his preferred view is not still a 'comparative one' (comparative to the maximum), or how the last imagining will fit with even Metz's own account. Nevertheless, whatever weight one gives to his main point here will be the weight that one gives to the desirability of relativizing to the maximum, characteristic maximum, or what have you, rather than the average, median, mode or what have you. The issues bear further reflection, but we may leave undecided the question of whether, if one is attracted to the relative understanding of meaningfulness, one should prefer a Relative-to-Average or a Relative-to-Maximum account of it, as, whichever way one calls that, it won't affect the argument of the current paper.

Let's then return to consider the situations of Gandhi and Tibalt.

In Atheism World, presumably the suitable comparison class when judging of a given person's life whether or not it is meaningful is the class of ante-mortem lives lived by human persons as - ignoring Martians and the like ${ }^{25}$ - they're the only persons and the ante-mortem lives lived by them are the only lives that any of them ever has. ${ }^{26}$ Of course, the presumption that this is the suitable comparison class could be challenged: why not say that the relevant comparison class is that of the lives led by an imaginary group of amazingly-long-lived humans, ones who have already completed, let's say, a millennium of very meaningful days? 
Stopping such a riposte to the Metz-inspired line of argument that I am seeking charitably to develop is an important task. Otherwise the argument that I am seeking charitably to develop will bite against the view that we can even say of the ante-mortem life of Gandhi that it is meaningful in Atheism World. And that the ante-mortem life of Gandhi is meaningful is the common-sense judgement that Metz is aiming to show the theist who endorses Universalism has an additional level of difficulty in making, additional that is to any that may be had by the atheist. But, supportive of Metz at this point, we can observe that there is something odd about appealing to a class of entirely imaginary 'millennial humans' as providing suitable comparators in Atheism World, and the source of that oddness is surely very plausibly that humans who live for millennia, whilst not physically impossible, are in fact non-actual in Atheism World. That non-actuality seems to be of relevance to explaining why appealing to the lives led by them by way of staking out a comparison class is not suitable. In further support of this point and thus Metz, consider the following. ${ }^{27}$

Suppose one day we are visiting that which we suppose to be, by a large margin, the biggest actual stately home; we thus judge of it that it is big. Surely, we would be right not to be shaken - even for a moment - from the judgment that this stately home we are visiting is big by someone who is visiting it with us and points out that if we imagine a set of 100 possible stately homes, each of which has a floor area of between ten and twenty times that of the stately home we are currently visiting, then (in comparison to that class of stately homes) the one we are currently visiting is not big. That just seems manifestly irrelevant. We would, by contrast, be shaken if our interlocutor pointed out that this set of 100 larger stately homes that we have just imagined is not in fact merely a figment of our imagination, but 100 such homes actually exist. We would then concede that that was at least relevant. Of course, if there are thousands of stately homes and the one we had said was big was still a notch or two above the average, median, mode or what have you for the class (for that account) or perhaps even one not a good notch or two below the maximum (for the account Metz himself might prefer to press at this stage ${ }^{28}$ ), we might - having been shaken momentarily by the news of these yet bigger 100 - nevertheless eventually continue to endorse our original claim that this one we are visiting is big. ${ }^{29}$

So, there is at least some support for saying that it is the lives led by actual people which form the relevant comparison class, from which an average, median mode or a maximum is then to be derived. And, if so, then thinking of what it is for a life to be meaningful as for it to be a notch or two above the average line or not more than a notch or two below the maximum line means we can certainly say the following. In Atheism World, someone amongst the top-scorers (as we may suppose Gandhi to have been) should be described as having a meaningful life and someone amongst the bottom-scorers (as we may suppose Tibalt to have been) should be described as having a meaningless one. To repeat the underlying point: this is because to lead a meaningful life one has to be above (perhaps by a notch or two) the average, median, mode (or what have you) or alternatively one has to be not below (by a notch or two) the maximum (or what have you). If one falls below (perhaps by a notch or two) the average or if one falls below (perhaps by a notch or two) the maximum, one leads a meaningless life. And, in the middle, things become indeterminate (which is, it will be recalled, the primary reason why I am talking of being 'notches or two' above or below). In this sense of meaningfulness then, we wouldn't say that Tibalt had a somewhat meaningful life, but just one far less meaningful than Gandhi. We'd say that, in virtue of his falling so far below the average, median, mode, or what have you or so far below the maximum, he had a meaningless life. This is just as we wouldn't say of a house that was in fact only - say - 9 sqm that it was big, just not as big as the average, median, mode or what have you of houses 
in Oxford or as big as the maximum-sized house in Oxford, but would instead say that it was small. That a house has some absolute size is not sufficient to make it big. It has to have a size which is relatively big, relative that is then to some - perhaps vague - sort of average as held by those in the suitable - if perhaps itself vague - comparison class or relative that is to some - perhaps vague - sort of maximum as held by those in the suitable - if perhaps itself vague - comparison class. According to this view then, there is no absolute sense of meaningfulness, just the relative one, and, given that and where he falls on the scale determined by the suitable comparison class, Tibalt's life is in fact meaningless and Gandhi's is in fact meaningful. So, how does all this help with Metz's case?

In Theism-Plus-Universalism World, one could of course use the same comparison class - the ante-mortem lives led by actual people. If one did, one would come up with the same judgement. Gandhi's life (in the sense of his ante-mortem life) was meaningful (by reference to the comparison class of ante-mortem lives) and Tibalt's was meaningless (again by reference to the comparison class of ante-mortem lives). So far, so similar; and so good. Though it is not so good for the Metz-inspired argument that I am at this stage seeking charitably to develop. It is not so good for this, as one may just rest one's case against the Metz-inspired argument at this point: why say that this ceases to be the suitable comparison class as one considers Theism-Plus-Universalism World, when it was the suitable class when one considered Atheism World? Metz might simply assert that it does cease to be suitable; that, he could say, is simply his view. But one might at least ask him if he has any justification for it. I can't actually see on Metz's behalf a way to respond to such a question with a justification that doesn't seem ad hoc. And Metz himself, it will be recalled, in the end wished to build into the conditions demarcating the suitable comparison class of lives the condition that they be lives lived within the natural world (with the physical laws being as they are). But he need not have built that in and, supposing he were not to do so, this would offer hope to a Metz-inspired argument - there are other comparator lives to which one might appeal in Theism-Plus-Universalism World without violating the 'actuality constraint'. This is because, in Theism-Plus-Universalism World, Gandhi and Tibalt don't actually cease to exist at death; they continue on post-mortem, and they continue on ad infinitum. So, it is also true that one could choose to use the comparison class of, say, the ante-mortem-plusgoogol $^{30}$-days-of-post-mortem lives lived by people without straying out of the realm of actual lives. In Theism-Plus-Universalism World, actual people live lives with googol days post-mortem sections. So, the route to using them as the members of the suitable comparison class is at least not blocked by their non-actuality. And choosing the lives of those who've had their ante-mortem lives and googol days of post-mortem life as the comparison class does generate problems for saying of Gandhi's ante-mortem life that it is meaningful in this relative sense, which then is the conclusion that the Metz-inspired argument is aiming for. And it is the conclusion aimed for reached via a route such as that suggested by the passages from Metz which I started by quoting. Let's see then how this Metz-inspired argument would play out.

Here is the table for Gandhi and Tibalt in Theism-Plus-Universalism World after googol days in Heaven.

Table 5: Theism-Plus-Universalism-World, After Googol Days in Heaven

Amount of meaningfulness

$\begin{array}{llll} & \text { Ante-mortem } & \text { Post-mortem } & \text { Total } \\ \text { Gandhi } & 1000 & \text { Googol D } & 1000 \text { plus Googol D } \\ \text { Tibalt } & 5 & \text { Googol D } & 5 \text { plus Googol D }\end{array}$


The figures in the total column here for Gandhi and Tibalt differ to a negligible extent. (We may suppose that a difference of 995 is negligible when compared to googol D and that googol D is so large as to make 1000 in itself negligible [it'd be odd if 995 were negligible but 1000 not, after all]). ${ }^{31}$

What then should we say if using this relative sense of meaningfulness and if conceding that the suitable comparison class when judging Gandhi's ante-mortem life's meaningfulness is the class of people who have died and had googol days in Heaven?

Perhaps initially we might be tempted to think that we should say that Gandhi's life (understood as ante-mortem plus googol-days post-mortem) is meaningful but Gandhi's life (understood as ante-mortem life alone) is meaningless, dwarfed into meaninglessness by googol-days' amounts of meaningfulness. Gandhi's life, as ante-mortem life, is dwarfed into meaninglessness by his (and everyone else's - we are, remember, supposing Universalism) life, as ante-mortem plus googol-days post-mortem life. The average, median, and mode of meaningfulness for everyone in the suitable comparison class is around googol D and the maximum is around googol D too. So, everyone's ante-mortem lives are certainly a notch or two (if not considerably more) below the average, median, or mode and everyone's antemortem lives are certainly a notch or two (if not considerably more) below the maximum. And this is precisely the sort of conclusion that Metz was aiming for: the theist (who is also a universalist) cannot consistently say that Gandhi's ante-mortem life is meaningful due to the fact that, on his or her worldview, Gandhi will actually lead a life the meaningfulness of later sections of which dwarfs into meaninglessness this ante-mortem section.

Contra some of Metz's claims, it is still true that the theist who is a universalist can say that if we are in fact - contrary to his or her beliefs - living in Atheism World, then Gandhi's life is meaningful, for then the right comparators are the ante-mortem lives lived by people. ${ }^{32}$ But that, I take it, will be little comfort for the theistic universalist who wants to preserve common-sense. He or she wants to say with common-sense that whether we're in Atheism World or Theism-Plus-Universalism World, Gandhi's ante-mortem life is meaningful and this is the sort of claim that this Metz-inspired argument appears to have blocked off from him or her.

What on this view should we say of Tibalt? Perhaps we should say that Tibalt's life (understood as ante-mortem plus googol-days post-mortem) is meaningful, and only negligibly less meaningful than Gandhi's life (understood as ante-mortem plus googol-days post-mortem). And then we should say that Tibalt's life (understood as ante-mortem life alone) is meaningless, dwarfed in the same way as Gandhi's ante-mortem life is dwarfed. (Of course, it had been dwarfed 'already', even when considering the comparison class of antemortem lives; still, it's dwarfed yet more now; it's 'even more meaningless' now.) And all of this is of a piece with what Metz says in the passages quoted at the beginning of this paper.

However, on further reflection, that can't be quite the right set of things to say, for it just kicks the can down the road. However much meaning a life has accumulated by any given time in Theism-Plus-Universalism World, there is so much more still to come that that amount will be dwarfed into insignificance by any arbitrarily large (but sufficiently large) section of it. As the post-mortem sections of each of Gandhi's and Tibalt's lives are without limit, so, we may say, there will come a day when their lives understood as ante-mortem plus googol-days post-mortem are similarly dwarfed into meaninglessness by the greater 
magnitude of meaningfulness of their lives understood as ante-mortem-plus-googol-plus(googol-squared)-days-post-mortem lives. That comparison class dwarfs into meaninglessness the comparison class of ante-mortem-plus-googol-days-post-mortem lives, the meaningfulness of which was used to dwarf into meaninglessness the ante-mortem lives of Gandhi and Tibalt. But if all that is so, aren't we just discovering that we can never 'get started', as it were, on the dwarfing programme, as we can never find any lives led which are meaningful, which are definitively above the average, median, mode or what have you or which are definitively near or at the maximum? For any table we draw up, the meaningfulness of the lives led by people as detailed on it will be dwarfed by another table we could draw up, one that just looks the necessary (for dwarfing) distance farther along the road. Well, yes, but this itself could be presented as something of a success for the Metzinspired argument. Positing a never-ending meaningful afterlife in the manner of Theism plus Universalism makes it impossible to say of any ante-mortem life that it is meaningful or indeed meaningless. Indeed it makes it impossible to say of any actual life - ante-mortem section alone; ante-mortem plus x-days post-mortem for any value of $\mathrm{x}$; and so on - that it is meaningful or meaningless, for no life that is or will ever actually be led by anyone in Theism-plus-Universalism World does or will ever fall a good notch or two above or a good notch or two below the average, median, mode or what have you as there is no average, median, mode or what have you and nor can any be near to or far from the maximum as there is no maximum. Or at least this is so if one is allowed to choose any comparison class of actual lives as led up to any time as a suitable comparison class for such judgments.

At this stage though, I think we might wonder - in any case, I do wonder - as to whether or not the oddness of these results gives us reason to think of what we are doing as providing a reductio of the way of thinking that leads to them. Whilst one could accept the relative way of thinking about meaningfulness - that for a life to be meaningful it must be above the average, median or mode meaningfulness of a suitable comparison class or not significantly below the maximum of that class - and challenge the suitability of the classes that lead to the odd results just sketched, it seems to me that the relative way of thinking about meaningfulness is itself questionable. Or rather that it is questionable as the whole account of how judgments of meaningfulness work. Indeed, it seems to me that it cannot be the whole account, for these relative judgments are always parasitic upon absolute ones and this parasitism gives us reason to think that no argument along the lines I have been seeking to develop from these passages in Metz will enable him to reach his desired conclusion. So I shall now argue.

Compare size. There is, it seems to me, a notion of something's being 'sizeable', which does indeed work solely in the relative sense, meaning the same as 'big'. For a house to be sizeable is for it to be of greater size than the average. Or perhaps it's for it to be not appreciably below the maximum. Thus, on the average account, it is true - if not immediately obvious - that were all houses made to the same size, none would be sizeable, just as none would be big. That would not follow on the maximum account (which similar result with respect to meaningfulness is indeed, it will be recalled, why Metz preferred the maximum account to the average one of that notion). On the maximum account of 'sizeable-ness', if all houses were the same size, all would be sizeable, however small they might be in absolute terms. That may itself seem a bit strange, of course. ${ }^{33}$ But when it comes to choosing between the 'Relative to Average' and 'Relative to Maximum' notions in these areas, it seems to me 'You pays your money; you takes your choice.' ${ }^{34}$ In any case, there is, more basically than any of this, a notion of size as a measure, in the context of houses, of their absolute floor area, such that, even if all were the same size and thus none was sizeable (on the average 
account) or all were (on the maximum account), they would still all have (the same) size. And if, having made all houses to the same size, we then doubled the size of all houses, whilst again none would be sizeable (on the average account) or all would be so (on the maximum account), each would have doubled in size. Something would have changed in absolute terms, even if nothing had changed in relative ones. The question to ask here is 'How could a notion such as sizeable work without this more basic notion of size?' And the answer is that it couldn't. We need some absolute for the relative, to set up the possibility of there being an average, median, mode or what have you or to set up the possibility of there being a maximum or what have you in whatever we select as the suitable comparison class. Thus, I suggest, the absolute notion is more 'basic' than the relative one; thus, the relative is 'parasitic' upon it. And thus, even if in some situations the notions of a house being sizeable or a life having meaningfulness in the relative sense become inapplicable, the more basic notions of size and absolute meaningfulness do not thereby become inapplicable, as the examples just given illustrate.

If this is right, we do best to think that meaningful does not work solely like 'big' or 'sizeable', where 'big' and 'sizeable' are understood to be 'a notch or two above the average' or 'not a notch or two below the maximum'. It also - and more fundamentally - works like size or some such, whereby something has a size simply if it occupies space, however small it might be relative to other things that have size. A mouse has a size; so too does an elephant. They would continue to do so even if they were transplanted into a universe that was of infinite size (I presume our universe is not of infinite size). And we can make comparative judgments of their size even if they are transplanted to a universe of infinite size. An elephant has a greater size than a mouse and that remains so even in a universe of infinite size - even if there's actually something of such great size as to make whatever absolute size they both have negligible relative to that other thing as comparator. But if that is right, if meaningfulness has an absolute and not simply a relative usage, then the odd results that Metz is aiming for cannot be reached and thus the quantitative point stands (or at least has not been shown by a new argument not to stand). ${ }^{35}$ So, let's bring these strands together.

In Theism-Plus-Universalism World, the heavenly post-mortem sections of our lives are destined to enhance their meaningfulness and - given their everlastingness - enhance that meaningfulness without limit relative to what meaningfulness our lives have in otherwise similar worlds in which Atheism is true and we have no such afterlife. Compare again the total column in Table 1 with those in Tables 3 and 4 . Now consider generating such tables $a d$ infinitum for successive days in Heaven, adding $\mathrm{D}$ each time to the post-mortem and thus total columns. One can do this with ease and appreciate that the pattern need never break down. ${ }^{36}$ We can still in consistency, if we suppose ourselves to be in Theism-PlusUniversalism World, judge as absolutely meaningful the first - ante-mortem - sections of lives. In Theism-Plus-Universalism World, our ante-mortem lives are as absolutely meaningful as they are in otherwise similar worlds in which Theism is not true and our antemortem lives are all the lives that we have - as they are in Atheism World as we have described it. Compare again the ante-mortem column in Table 1 with those in Tables 3 and $4 .{ }^{37}$ The common-sense intuition, that a meaningful life is possible even if ours is a world with no God or Heaven awaiting us, is right. It's just that even more meaningful lives are possible and indeed are our destiny if we do in fact live in a world such as Theistic Universalism describes. As, in worlds in which Theism and Universalism are true, with time the same absolute post-mortem addition of meaningfulness is made to the lives of Gandhi and Tibalt (or so I have been assuming; D per day), so the relative differences between the two diminish with time, tending to nothing over the span of eternity. Theism plus Universalism 
(on the equality assumption) makes our individual lives (considered correctly then as composed of ante-mortem plus post-mortem sections) an ever-finite-yet-ever-increasing amount more absolutely meaningful than they are in atheistic worlds, or at least those atheistic worlds where our lives are considered correctly as composed of their ante-mortem sections alone. And that does mean, in deference to Metz, that, on the equality assumption, Theism plus Universalism makes our lives (considered correctly then as composed of antemortem plus post-mortem sections) of ever-decreasing relative difference in their meaningfulness. And it means that there will come a day on which we should say of Gandhi's ante-mortem life that it is to be judged (on that day) as of negligible meaningfulness relative to the life which he will by that day have behind him (ante-mortem life plus googol days of post-mortem life, if no day earlier suffices); googol D plausibly dwarfs into negligibility 1000. See again table 5. And it means that there will come a day (e.g. googol plus googolsquared days into Heaven, if no day earlier) on which even that fades to negligibility in compassion to what by then will have been achieved. And so on, ad infinitum. But that does not seem to be at all counterintuitive. And it leaves unaffected - indeed it presupposes - the never-ending addition to the absolute meaningfulness of Gandhi's life, progressing as antemortem plus post-mortem life. No matter how much meaningfulness it's our destiny to receive, that future cannot diminish the absolute amount of meaningfulness we have at any time received.

Most of us are blessed with absolutely meaningful ante-mortem lives. We rightly hope that death is not the end and that yet more absolute meaningfulness awaits us on the other side. In hoping that those post-mortem additions will continue ad infinitum, we are indeed hoping for something which, if it comes, will lead to a decrease in the meaningfulness of our ante-mortem lives relative to it. We are hoping for something which will eventually lead to our ante-mortem lives being of negligible meaningfulness relative to what, by then, we will have enjoyed - decreasing their meaningfulness (relative to that) whilst of course not decreasing their absolute meaningfulness at all, indeed whilst (and precisely because) adding to the absolute meaningfulness of our ongoing lives, adding ad infinitum. ${ }^{38}$

17.01 .20

\section{References}

MAWSON, T. J. (2010), 'Sources of Dissatisfaction with Answers to the Question of the Meaning of Life', European Journal for Philosophy of Religion, Vol. 2, no. 2

MAWSON, T. J. (2016a) 'What God Could (and Couldn't) do to Make Life Meaningful', in J. Seachris and S. Goetz (eds), Theism and the Meaning of Life: New Essays (London: Bloomsbury)

MAWSON, T. J. (2016b) God and the Meanings of Life (London: Bloomsbury)

MAWSON, T. J. (2017) 'An Agreeable Answer to a Pro-Theism/Anti-Theism Question', in Klaas J. Kraay (editor), Does God Matter? (New York: Routledge), 70-92

MAWSON, T. J. (2018) 'God's Possible Roles in the Meaning of Life; Reply to Metz', European Journal for Philosophy of Religion, Vol 10, no. 3

MAWSON, T. J. (2019) Monotheism and the Meaning of Life (Cambridge: CUP)

MAWSON, T. J. (Forthcoming) 'Does Anything We Do Matter Forever?', Religious Studies

METZ, T. 'Imperfection as Sufficient for a Meaningful Life: How Much is Enough?', in Y. Nagasawa and E. Wielenberg (editors.), New Waves in Philosophy of Religion (New York: Palgrave Macmillan), 192-214

METZ, T. (2017) 'Meaning in Life' in Y. Nagasawa and B. Matheson (eds.) The Palgrave Handbook of the Afterlife (London: Palgrave Macmillan), 353-370

METZ, T. (2018) 'God's Role in a Meaningful Life. New Reflections from Tim Mawson', European Journal for Philosophy of Religion, Vol 10, no. 3. 171-191 
METZ, T. (2019) God, Soul and the Meaning of Life (Cambridge: CUP)

SWINBURNE, R. (2016) 'How God Makes Life a Lot More Meaningful', in J. Seachris and S. Goetz (editors), God and Meaning: New Essays (London: Bloomsbury)

\section{Notes}

${ }^{1}$ The contemporary literature is often self-confessedly focused on what it thus calls the 'meaning-in-life' issue to distinguish its concerns from attempts to address what are sometimes then called more 'holistic' or 'cosmic' meaning-of-life issues - Why is there anything at all? Where is it all going?

${ }^{2}$ See my (2010), 19-41; my (2016a); my (2016b); my (2018); and my (2019).

Having pushed it on stage in this paragraph in the main text, I shall now seek to push my own 'polyvalence' view off stage, so as to meet the Metz-inspired argument on its own grounds; I think that the Metz-inspired argument that I shall develop can be met without drawing on my own (controversial) polyvalence view of meaningfulness. Why then (other than for reasons of 'full disclosure') sketch my own view at all? So that I may, in this footnote, indicate other avenues of response to the Metz-inspired counter-argument, ones which are available to me even if not to those who do not share my polyvalence view.

Given my polyvalence view, I might say that whilst Metz is right about some types of meaningfulness (on Theism plus Universalism, Gandhi's ante-mortem life gets a 'flat zero' or something near enough with respect to some types of meaningfulness, whereas on Atheism, he gets a high score), he is wrong about others (there are other and deeper types of meaningfulness that Gandhi gets by way of compensation - and more than compensation - on Theism plus Universalism). (See, in addition to the works cited already, my forthcoming.) Also, on my view, there are types of meaning (even if arguably by terminological fiat these cannot be counted as types of meaningfulness) that an individual's ante-mortem life may get post-mortem even without personal survival post-mortem; I tend to use Anne Frank as an example that illustrates this - most of the this-worldly meaning that her life had came after her death. If Metz were to admit this (and count some of them as types of meaningfulness), then a version of the Metz-inspired argument could arguably apply even in what I shall call Atheism World where he doesn't want it to work. Metz himself concedes this elsewhere, talking of 'ripples'; Nozick had talked of 'traces'. (I am grateful to Metz for himself pointing out in discussion that he concedes this point elsewhere.) Finally, on my view, God adds to the meaningfulness of our ante-mortem lives in various ways relative to how they are if Atheism is true, e.g. some of our projects get to fulfil a purpose in an appropriate larger scheme of things - a type of meaning, I argue, and quite a deep one (though again Metz would disagree, as would others). On Atheism, the purposive agent who would do this meaning-adding best is absent. Thus, whilst, in this paper, I keep the amount of ante-mortem meaningfulness fixed across the relevant worlds for the sake of argument, this is very much a 'solely for the sake of argument' sake of argument. For further discussion, see 'the qualitative point' in (my 2016 b, chap. 9 ff.) and (Swinburne 2016). I am grateful to Nick Waghorn for having discussed with me some of these other lines of attack which I could press, albeit only from premises that Metz himself would dispute.

${ }^{3}$ In my own experience, though a common first comment on this topic 'from the pew', as it were, might be that without God and Heaven, our lives here are entirely meaningless, on second pass, almost all believers concede that in fact, even if there is no God and Heaven, our earthly lives and some of the activities in them manage to have some 'relative' or 'transient' meaning.

${ }^{4}$ I have myself never met an atheist who think that this life is entirely meaningless due to the absence of God and the right sort of afterlife, though the view is represented in the literature.

${ }^{5}$ The issue is complicated by the fact that most theists are not universalists and thus, insofar as they entertain Theism as a live possibility, most agnostics and atheists tend to have in mind non-universalistic Theism. The argument of the main paper doesn't seek to explore how things would play out differently were one to adopt theistic views of our ultimate destiny other than Universalism. As I am myself drawn to the view that Universalism follows of logical necessity from a theistic God having created people such as us, I don't seek to explore what others will see as options here. In discussion, Metz points out that he would argue that whilst the main text reflects the current consensus, a more extreme supernaturalism would have been de rigueur in the Middle Ages. See, e.g. his (2019).

${ }^{6} \operatorname{Metz}(2017,2018$, and 2019)

${ }^{7}$ This paper is, readers will have already noticed, footnote-heavy; this is in part so as to gesture down pathways that are worthy of more exploration than that which can be accomplished whilst pursuing a (relatively) linear argument in the direction Metz has pointed for us. I especially encourage readers who disagree with the premises of my own response to Metz to explore these other pathways.

${ }^{8}$ Metz (2019), 30-3

${ }^{9}$ Metz (2018), 188

${ }^{10}$ This is not in fact an entirely non-problematic way of putting it. See, for example, my (2017). 
${ }^{11}$ For simplicity, in what follows, I shall be ignoring the possibility that some of us at least reach Heaven only via a spell in Purgatory. Adding Purgatory into the picture would require an extra sub-column under the 'Postmortem' heading in the tables to follow. Such a sub-column would complicate, but not fundamentally affect the case. Also for simplicity, I shall be assuming that time in Heaven passes in measurable intervals, which we may refer to as 'days'; again, such an assumption, if dropped, would not alter the fundamentals of the case, but would add complicating epicycles to the discussion at various stages. (I am grateful to Richard Swinburne for pointing this second point out to me.)

${ }^{12}$ In discussion, Metz concurs that these are all fair conditions to stipulate to enable one to come to grips with his argument.

${ }^{13}$ Martin Pickup has suggested to me in discussion that whilst, from the point of view of anyone in the universe, what I say may be right, if there is a coherent point of view from outside space-time, one might be able to think of someone from that perspective correctly thinking of completed actual infinities within the universe. I do not explore this option further in this paper, though for someone - like me - who is an atemporalist about God, such a perspective is not only possible, but actual. Perhaps one should say that God sees all our lives as equally - and infinitely - meaningful, even though none of us will ever correctly do so. I think there may be some resources within such thoughts to explain why God's infinite love for us is not in any problematic way disproportionate to our status, our status as $\mathrm{He}$ and $\mathrm{He}$ alone can correctly see it.

${ }^{14}$ Again, I am assuming for ease of presentation that time operates in Heaven as it does on Earth, but all that is necessary is that Gandhi and Tibalt receive their Ds in some coordinated way in Heaven. I am also assuming that $\mathrm{D}$ is finite - of metaphysical necessity, creatures such as ourselves could not receive infinite meaningfulness all at once. I am grateful to Martin Pickup and Steve Wright for drawing my attention to these points.

Of course, one needn't think that each resident gets the same amount of meaningfulness per day in Heaven. For discussion of some more options, see my (2016b), 156ff. A supposition of equality of rate of delivery of meaningfulness when it comes to heavenly afterlives is fair when seeking to engage charitably with the Metzinspired argument; I call it the 'equality assumption' about meaningfulness in Heaven. Metz considers a response to his argument which drops the equality assumption, substituting for it something which Metz admits would defeat his argument, but - Metz argues - would generate unacceptable (for the theist) collateral damage elsewhere. He says in a note, 'Matthew Hammerton has suggested in conversation that a life might be infinitely long in duration and continue to accrue meaning over time, but ever-increasingly to a lesser degree, so that it never achieves whichever amount of meaning would dwarf the meaning available to a finite life. It is an interesting move, but one then wonders whether this eternal life would, at a certain stage, be comparable to one in a permanent coma, which may be presumed to have some, small amount of meaning (say, in respect of loved ones), but not enough to make it worth continuing with.' (Metz, 2019, 31) I myself consider a variant of that move at one stage, one whereby people maintain their ante-mortem differentials in meaning-acquisition. So, supposing Gandhi and Tibalt had the same ante-mortem life-span, we may say that Gandhi acquired meaningfulness at an average rate which was 200 times greater than Tibalt's. On this model, in the afterlife, they would continue to show this disparity and hence the relative gap between their lives' meaningfulness not close (as it does on the equality assumption) as they continued on ad infinitum in their post-mortem lives. This would seem to be a variant then of Hammerton's move which is not itself susceptible to the counter-argument that Metz uses against Hammerton's move, though Metz himself might say it wouldn't then enable one to avoid what I call 'the dwarfing problem'. In any case, as I say, one is charitable to the Metz-inspired argument if one keeps the equality assumption in place.

${ }^{15}$ Of course, there are other arguments against this conclusion - e.g. those inspired by Williams-style reflections on the meaning-negating properties of immortality or those which suggest that it is only temporal finitude (in the forwards direction) which can bestow meaning on our choices in life. These other arguments though are besides my current purposes. By assuming - as I am - that D may be added each day in Heaven, I am assuming that such arguments can be defeated. This is not to say that arguments such as Williams's can in general be simply assumed to be defeasible, but only that, in this paper, I am interested in coming to grips with this new argument suggested by Metz as an argument which is such that, if it works, it works even if they are defeasible.

16 In discussion, Metz has in fact not disavowed it, but has addressed to me the consideration that 'more precisely... it's tough for you to capture [the thought] ... not that 'some meaningfulness is achievable in Atheism [World], but rather that 'a meaningful life' or 'a life that is on balance meaningful' is achievable.' I hope that what I shall have to say in the main text hereafter will show that this is not tough for plausible dis-ambiguations of 'a meaningful life' or 'a life that is on balance meaningful'.

${ }^{17}$ If one allows in an absolute sense in addition, then the argument that I am seeking charitably to develop on behalf of Metz becomes moot; the theist is unlikely to be troubled by conceding that, in relative senses of meaningfulness, things may happen in Theism-Plus-Universalism World such as Metz claims. As long as Gandhi's ante-mortem life remains absolutely meaningful and absolutely more meaningful than Tibalt's antemortem life, the truth of the common-sense judgement is secured. This is a point to which we shall return in the 
last few paragraphs of the main text in this paper. It is, as we shall see, rather too important to be left solely in a note.

${ }^{18}$ In discussion, Metz concedes that his own variant would not 'make a difference' to what I have to say.

${ }^{19}$ Metz (2009)

${ }^{20}$ Metz, (2009) 207

${ }^{21}$ Metz, (2009) 208

22 Metz (2009) 210

${ }^{23}$ Metz (2009) 203

${ }^{24}$ Metz (2009) 204

${ }^{25}$ Of course, this raises the issue of why, on Metz's view, we should ignore Martians if we can't be sure that none are actual. He might reply by pointing to the fact that of course Martians, even if actual, are not humans and insisting that suitable comparison classes for judgments of a human's life's meaningfulness must always be made up of actual humans. However, the concern would then simply shift to the issue of what rationally motivates such 'speciesism'. Metz's problems do not end there. Granting speciesism, one could press a version of Metz's own 'incoherence objection' on him. Metz seems committed to the view that he knows Gandhi's life is meaningful; he knows that if there were actually ever going to be humans who, due to medical and lifeextension technologies lived for, say, a millennium and were able to enjoy significant meaningfulness throughout, then Gandhi's life would not be meaningful; so - according to his own lights - it is 'incoherent' for him to claim that he does not know that such advances in medical and life-extension technologies will never be made. But being able to know this 'from the armchair', as it were, given only the common-sense judgment that Gandhi's life was meaningful, isn't a result it seems Metz should welcome. There is something very odd about someone sitting in an armchair reading a biography of Gandhi and thence formulating common-sense knowledge of Gandhi's life's meaningfulness then being able to conclude that medical and life-extension technologies will stall. Martin Smith has pointed out to me in conversation that Metz seems, by his own logic, similarly committed to the view that he can know from the meaningfulness of Gandhi's life that certain multiverse hypotheses are false, which again would not be a result he should welcome.

${ }^{26}$ It will be recalled I am ignoring atheistic views whereby something that is not God nevertheless manages to give us some sort of afterlife. Again, this is being charitable to Metz. 'Why ignore such views?' is a question one might press him on.

${ }^{27}$ Metz is not always his own best friend here, referring at one stage (Metz (2019), 31) to its being apparently permissible to refer to merely 'potential lives' when seeking comparators.

${ }^{28}$ It depends on how one thinks of notches; if the maximum floor area really is ten to twenty times that of the house we're visiting, then plausibly the house we're visiting is a notch or two below the maximum.

29 Martin Pickup points out to me in discussion that for some judgments it might seem relevant how meaningful/big things could have been (even if none ever are). Consider speed. There is - it is widely held - a physical limit to the speed anything can achieve in our universe, the speed of light; nothing can - even in principle - travel faster than the speed of light. Let's suppose that's right and let's suppose that the fastest spaceships ever actually developed only manage to travel at one thousandth of the speed of light. Given all of that, it does not seem unnatural to say that all spaceships are destined to be slow, slow not then by reference to any average or maximum speed achieved by any actual spaceships (for that trivially generates as an impossibility that all be slow), but slow relative to how fast they could have gone, in principle. A refusal to recalibrate in some way by reference to actual spaceships, so as to generate trivially the fact that the fastest spaceship ever produced will be fast doesn't seem to me, I concede, obviously a conceptually misguided way of thinking about what it is for a spaceship to be fast. In discussion of my example as given in the main text, Metz reports that he'd be keen to know whether such massive homes 'were likely, even if they didn't exist' (as they'd perhaps then be relevant). And Nick Waghorn has made a similar point to me in the context of discussing meaningfulness, arguing that if it is metaphysically possible that our lives be significantly more meaningful than any actually are, that too might license one in saying of all our lives that they are not meaningful, again not by reference to the average or maximum in a comparison class made up of actual lives led. Waghorn himself favours such a view. These lines of thinking are worthy of further exploration.

Finally, in this context, Metz himself says the following in discussion. 'Suppose the interlocutor invites me to consider whether I would judge my house to be big compared to these possible 100 stately homes. Then I would say 'no'. Similarly, when someone claims that eternal life in Heaven would give me a potential infinity of meaning compared to the dollop available on earth, I'm being invited to consider whether I would judge my dollop to afford me a life aptly described as 'meaningful' compared to a potential infinity. My answer: 'No'.' I concede that this is plausible - much depends, as always, on what comparison class one has (or, in this case, is told to have) in mind when considering the question. The penultimate paragraph of the main text of this paper (where I talk of what must be conceded 'in deference to Metz') shows quite where I agree and where I disagree with Metz on this point. 
${ }^{30}$ That is ten to the power of 100 .

${ }^{31}$ I am supposing in all this that the afterlife starts for everyone at one time, subsequent to the deaths of everyone. If the afterlife is already 'up and running' and has been for some millennia prior to the deaths of Gandhi and Tibalt, then there will already be people whose addition of Ds plausibly dwarfs Gandhi's score of 1000 as he had reached it at the moment of his death.

${ }^{32}$ Metz himself, in discussion, demurs (to an extent) at this stage. 'One can (probably should) view the objection I'm making dialectically: If you, contemporary theist, have us compare the infinite meaning available in a spiritual world with the finite degree available in a purely physical world (not that I, Metz, think you should do that!), then you cannot conclude that a life aptly described as 'meaningful' is possible in the latter world...But you, contemporary theist...should want (vide Gandhi) to conclude that a life aptly described as 'meaningful' is possible in a purely physical world.'

${ }^{33}$ And I should note that Metz did not himself apply this standard to size.

${ }^{34}$ One of the anonymous referees for this journal expressed puzzlement at this colloquial phrase; perhaps it is more current in UK-English than in other forms. It has elements of 'Buyer beware' and 'You've made your bed, now lie in it.'

${ }^{35}$ At this point, in discussion, Metz himself falls back on his comparison with 'happy', saying that whilst he accepts that 'we can say that life $\mathrm{X}$ has some meaning, while life $\mathrm{Y}$ has more...the relevant thing to capture...is not that. It is instead that life $\mathrm{X}$ is aptly described as 'meaningful, in the way we might want to characterize someone's life as 'happy' on balance.' But it seems to me that happiness as a notion doesn't help Metz make his case here. Indeed, if anything, it needlessly undercuts it, as happiness obviously does have an absolute sense and it is far from obvious that it has a relative sense. Consider the following. If someone lived a life of a hundred years and, during that period, had only a day that we would wish to describe as an unhappy one (every other day of the hundred years being one which we would wish to describe as happy), they lived, I think we would all say, a happy life, a life that was 'happy on balance'. And I don't think we'd be inclined to revisit that judgment if we were told that they had lived this life in a universe in which most people led lives of a thousand years during which they had only half-a-day's unhappiness (the remainder of their days being happy ones). We wouldn't be inclined to say something along the lines of, 'Well, in that case, the life of the first person was unhappy.' We would of course be willing to add to our judgment that the first person had led a happy life (one that was happy on balance) other judgments, e.g. the judgment that they were not as happy as the majority or as the average or what have you. We might even - in a concession to Metz - be prepared to add the judgment that that there was some comparison class of actual lives led which so outperformed the life that this individual led as to make it true that in a relative sense (should we wish to allow one), they were - compared to them - 'unhappy'. Though, even as I consider this concession, I feel I should note that to me it does sound odd to say that in any sense they were unhappy, rather than simply 'less happy' than some. After all, they had only one day short of 100 years'worth of pure happiness. Thus, my scepticism about whether happiness has a relative sense at all. And thus, as I say in the main text, it seems to me that we can describe Gandhi's ante-mortem life as meaningful or meaningful on balance; it has, in my terms, absolute meaningfulness. By stipulation for the purposes of this argument, it has 1000 units of it. And that remains so even if there is to come for Gandhi a post-mortem life that will dwarf his ante-mortem life's meaningfulness in the relative sense of meaningfulness (should we wish to allow a relative sense of meaningfulness, as it seems to me, in fairness to Metz, one should concede there is a stronger case for allowing than there is a case for allowing a relative sense of happiness).

${ }^{36}$ Remember, I am ignoring Williams-type concerns that suggest one cannot add Ds ad infinitum and so the pattern would break down.

${ }^{37}$ Remember again when doing so that I am ignoring in this paper, so as to meet the Metz-inspired argument on its own ground, the fact that one might sensibly argue that the ante-mortem lives of people in theistic worlds are more meaningful than they are in atheistic worlds, through e.g. their existing for a purpose in an appropriate larger scheme of things and so on. Though I should note that of course some philosophers would argue that God would detract from our ante-mortem lives' meaningfulness.

${ }^{38}$ I am grateful to Martin Pickup and Nick Waghorn for their detailed comments on an earlier draft of this paper. I have not been able to include mention of all the points and differences of opinion that they suggested, quite rightly, were worthy of further consideration. I would also like to thank Stewart Goetz, Martin Pickup, Richard Swinburne, and Steve Wright for talking to me about a later iteration of the paper at Oxford's Philosophy of Religion Work in Progress Group. Again, I have not been able - for reasons of space - to include mention of all their points. I am also very grateful to Thad Metz for looking at what proved to be the penultimate draft (prior to my submitting it to this journal); he was perhaps more charitable to me than I have been to him. And, finally, I am grateful to the two reviewers for Religious Studies whose comments were also very helpful to me in finalising the paper for publication. 